\title{
COMÉRCIO ELETRÔNICO: UM ESTUDO DE CASO BASEADO NA BOLSA ELETRÔNICA DE COMPRAS DO ESTADO DE SÃO PAULO.
}

\author{
Marissa Yanara de Godoy Lima, Josélia Galiciano Pedro, Nilmaer Souza da Silva \\ Universidade do Oeste Paulista - UNOESTE. E-mail: joselia@unoeste.br
}

\section{RESUMO}

Em meio aos relevantes avanços tecnológicos registrados a partir da década de 90 , onde a utilização da internet tornou-se significativamente mais popular, a prática de comércio eletrônico passou a ser exercida entre pessoas e empresas do mundo todo, possibilitando relações sociais, econômicas e comerciais, até então inexistentes. Embora existam diversas maneiras de classificar as transações do comércio eletrônico, a mais utilizada pelos autores estudiosos do tema envolve diretamente os participantes da transação. Assim, nesta pesquisa, cujo foco principal é a Bolsa Eletrônica de Compras do governo do estado de São Paulo, será abordado o segmento G2B, ou governo-empresa, que refere-se às transações realizadas entre organizações privadas, e as instituições públicas, tanto municipais, quanto estaduais e federais. Quanto às características metodológicas, esta pesquisa foi elaborada utilizando-se de uma abordagem descritiva e exploratória, caracterizando-se como uma pesquisa qualitativa, utilizando métodos de estudo de caso. Desta forma, a partir dos resultados deste estudo, tornou-se ainda mais evidente a importância do comércio eletrônico em meio ao cenário atual, salientando as funcionalidades da Bolsa Eletrônica de Compras e os benefícios e dificuldades enfrentados por quem opta por este segmento.

Palavras-chave: Comércio Eletrônico, Bolsa Eletrônica de Compras, Internet.

\section{E-COMMERCE: A CASE STUDY BASED ON BOLSA ELETRÔNICA DE COMPRAS OF THE STATE OF SÃO PAULO.}

\begin{abstract}
Amid the relevant technological advances made from the 90s, where the use of internet has become significantly more popular, the practice of e-commerce began to be exercised between people and companies around the world, enabling social, economic and trade relations hitherto nonexistent. Although there are several ways to classify e-commerce transactions, the most widely used by scholars of the topic authors directly involves participants of the transaction. Thus, in this study, whose main focus is the Bolsa Eletrônica de Compras government of the state of São Paulo, will address the G2B segment or company-government, which refers to transactions between private organizations, and public institutions, both municipal, and state and federal. As for the methodological characteristics, this research was constructed using a descriptive and exploratory approach, characterized as a qualitative research using case study methods. Thus, from the results of this study, it became even more evident the importance of electronic commerce amid the current scenario, highlighting the features of the electronic trading cart and the benefits and difficulties faced by those who choose this segment.
\end{abstract}

Keywords: E-commerce, Bolsa Eletrônica de Compras, Internet 


\section{INTRODUÇÃO E OBJETIVO}

Em meio aos relevantes avanços tecnológicos registrados a partir da década de 90 , onde a utilização da internet tornou-se significativamente mais popular, a prática de comércio eletrônico passou a ser exercida entre pessoas e empresas do mundo todo, possibilitando relações sociais, econômicas e comerciais, até então inexistentes.

Embora existam diversas maneiras de classificar as transações do comércio eletrônico, a mais utilizada pelos autores estudiosos do tema envolve diretamente os participantes da transação.

Conforme Laudon e Laudon (2007, p. 280), "as três principais categorias do e-commerce são: comércio eletrônico empresa-consumidor, comércio eletrônico empresa-empresa e comércio eletrônico consumidor-consumidor".

O comércio eletrônico empresa-consumidor (B2C) abrange a comercialização varejista de serviços e/ou produtos a consumidores finais.

Conforme Turban e King (2004, p. 75):

As vendas por catálogo livram o varejista da necessidade de ter uma loja física a partir da qual possa distribuir produtos. Para o cliente, a vantagem é poder consultar os catálogos quando quiser, em vez de ter de se deslocar até a loja. Logo, com a presença da Internet, o próximo passo lógico para o varejo seria passar para a venda on-line. Vendas de varejo on-line são denominadas varejo eletrônico ou e-tailing.

A partir das considerações do autor, é possível compreender que o varejo eletrônico, ou etailing, agrega benefícios tanto para o empreendedor, que não precisa investir em uma loja física para comercializar seus produtos, quanto para o consumidor, que tem a comodidade de conhecer os produtos oferecidos por determinada empresa, bem como as informações provenientes de sua escolha, sem mesmo deslocar-se à loja.

O comércio eletrônico empresa-empresa consiste na comercialização de produtos e/ou serviços entre empresas.

Embora o comércio eletrônico B2B não seja tão divulgado pela mídia, quanto as comercializações destinadas aos consumidores finais, de acordo com Ramos et al., (2011, p. 141), "em 2010, o valor transacionado nas operações de comércio eletrônico B2B representava 63\% do mercado total, enquanto o comércio eletrônico representava $29 \%$ dos negócios totais de varejo". Desta forma, baseado nos dados levantados pelos autores, é possível compreender que as transações realizadas entre empresas já correspondem a maior parte das negociações eletrônicas. 
Assim, visto a aderência das organizações ao e-commerce e a fatia considerável ocupada pelo comércio eletrônico $\mathrm{B} 2 \mathrm{~B}$ em meio às transações online, subentende-se que inúmeros benefícios vêm sendo agregados às organizações que fazem parte desta estatística, independe do seu segmento ou tamanho.

O comércio eletrônico consumidor-consumidor (C2C) pode ser definido como a comercialização online de produtos e/ou serviços entre consumidores finais.

De acordo com O’Brien (2010), este segmento de comércio eletrônico pode ser considerado uma importante estratégia de negócios visto o enorme sucesso que estão obtendo os sites de comercialização entre consumidores. Assim, evidencia-se portanto que os consumidores não precisam atuar necessariamente como simples compradores, mas por meio de sites especializados, podem oferecer seus produtos ou serviços a outras pessoas.

Além das categorias apresentadas pelo autor supracitado, existe ainda outra modalidade que tornou as tarefas realizadas pelo governo muito mais ágeis, eficazes e transparentes, onde é possível a qualquer cidadão acompanhar muitas das negociações feitas pelo Estado, principalmente no que diz respeito à contratação de serviços ou aquisições de bens. Esta categoria é definida como: comércio eletrônico governo-empresa (G2B).

Assim, G2B refere-se ao e-commerce no qual o governo vende à empresas e lhes presta serviços, bem como as empresas vendem produtos e serviços ao governo. (TURBAN; KING, 2004, p. 244). Entende-se, portanto, que através desse tipo de comércio eletrônico, a sociedade de uma maneira geral é beneficiada, visto que por meio das transações efetuadas pelo G2B inúmeras facilidades são obtidas e os processos tornam-se bem menos burocráticos.

Desta forma, essa pesquisa tem por objetivo, conceituar o comércio eletrônico e suas principais categorias, bem como apresentar a Bolsa Eletrônica de Compras do Estado de São Paulo e sua funcionalidade. Serão discutidos os principais benefícios e barreiras enfrentadas por este tipo de comércio, a fim de destacar as oportunidades e necessidades deste mercado, que encontra-se cada vez mais competitivo.

\section{Bolsa Eletrônica de Compras do Estado de São Paulo}

Tendo em vista a importância da prática de comércio eletrônico, principalmente no que diz respeito às transações realizadas entre governo e empresas (G2B), como resultado desta pesquisa, será apresentada a Bolsa Eletrônica de Compras do Estado de São Paulo - BEC, onde todos os órgãos públicos, autarquias, e empresas públicas já contam com um sistema informatizado para 
divulgação de suas necessidades de bens e serviços por meio da Internet, e através da BEC são abertas licitações para contratação de prestadores de serviço e aquisição de suprimentos.

Conforme estudos realizados por Costa (2004, p. 28):

As compras de governo são, em geral, lentas; às vezes, envolvem corrupção, equipamentos que se tornam obsoletos ou se deterioram, estoques muito grandes ou perigosamente curtos: a lista não tem fim. As compras on-line podem ajudar a sanar todos esses problemas. Ganha-se muito em termos de transparência do processo e abre-se uma maior possibilidade de participação para as pequenas empresas.

Assim, buscando resolver os problemas levantados pelo autor e proporcionando uma maior transparência e credibilidade em relação às transações realizadas pelo governo, aos 18 de setembro de 2000, por meio do Decreto no 45.085, de 31 de julho de 2000, foi instituída pelo Governo do Estado de São Paulo, a Bolsa Eletrônica de Compras.

Segundo o artigo 1ำ, do Decreto no 45.085 (SÃO PAULO, 2000), a partir de sua publicação oficial, ficou instituído no âmbito do Estado de São Paulo, o sistema de contratações, cujo funcionamento se daria baseado nas disposições deste. Assim, com o início de suas atividades, toda e qualquer transação entre o governo e empresas privadas, em relação à compra de suprimentos ou contratações de serviço, passou a ser efetuada por intermédio da BEC.

Este sistema foi desenvolvido e implantado pelo governo do estado de São Paulo com a finalidade de promover negociações de preço de bens e serviços adquiridos pela administração pública, direta e indireta do estado, estipulando condições justas de participação e propondo ampla competitividade entre os concorrentes. Desta forma, garante-se uma negociação eletrônica transparente que possibilita a aquisição de materiais e contratação de serviços de forma íntegra, proporcionando ao estado, uma economia considerável de custos referente às negociações.

\section{METODOLOGIA}

Além de proporcionar maior conhecimento sobre o assunto abordado e possibilitar o desenvolvimento do estudo discorrido, de acordo com Rampazzo (2004), a pesquisa permite o desdobramento de fatos e dados, teorias e práticas, independentemente da área de atuação.

Conforme estudos realizados por Creswell (2007, p.35), “a pesquisa qualitativa é basicamente aquela que busca entender um fenômeno específico em profundidade". Portanto, no decorrer da pesquisa e desenvolvimento do assunto abordado, cabe ao autor preservar a qualidade das informações coletadas, agregando maior valor ao trabalho elaborado. 
Assim, este trabalho apresenta-se de forma qualitativa, tendo em vista a explanação realizada sobre as funcionalidades e categorias do comércio eletrônico, baseadas diretamente nos participantes da transação.

Segundo Gil (2010), a consulta à fontes documentais é algo indispensável na elaboração da pesquisa científica, visto que, a coleta bibliográfica evidencia a contribuição de outros autores, adicionando maior credibilidade ao estudo. Com isso, torna-se evidente a importância da pesquisa bibliográfica, tendo em vista a abrangência das obras disponíveis e os estudos elaborados a partir das teorias levantadas.

O estudo de caso se caracteriza como um tipo de pesquisa cujo objeto é uma unidade que se analisa profundamente. (GODOY, 1995, p.25). Assim, aliada à coleta bibliográfica, a pesquisa científica de âmbito qualitativo-descritivo, torna-se muito mais concisa, permitindo a comparação entre a teoria encontrada nas obras pesquisadas, e o cotidiano vivenciado pelas organizações.

\section{RESULTADO}

A amostra selecionada foi composta pelos dois proprietários da organização estudada, que se fizeram fundamentais a realização desta.

Ao serem questionados quanto as principais vantagens em efetuar negociações diretamente com o governo, ambos afirmaram que a inexistência de risco com inadimplência pode ser considerado o principal fator de investimento neste setor, complementando ainda que o recebimento dos valores é totalmente seguro, baseado em editais e documentos públicos.

O fato das negociações entre o governo do estado e as empresas privadas serem realizadas por intermédio de um portal online, proporciona maior transparência e credibilidade quanto às transações, visto que às informações referentes às negociações, bem como valores, quantidade e procedimentos de compra e venda encontram-se disponíveis à qualquer cidadão. Assim, desde o início de suas atividades, a Bolsa Eletrônica de Compras do Estado de São Paulo - BEC/SP vêm concedendo às organizações, inclusive micro e pequenas, a possibilidade de firmar negociações diretamente com o governo, ofertando produtos dos mais variados segmentos em grande quantidade, mediante a segurança de recebimento em 30 (trinta) dias após a venda.

Embora existam três modalidades licitatórias disponíveis no sistema BEC, segundo o Decreto Estadual no 45.085, o foco principal do governo é possibilitar negociações de produtos de qualidade, que atendam as exigências da instituição requerente, com o menor preço possível. Assim, cabe a própria organização, optar por quais modalidades participar, visando a documentação exigida nas licitações e a agilidade do processo comercial. 
Tratando-se da concorrência, e das estratégias definidas para sobressair-se perante as organizações atuantes no mesmo segmento, os entrevistados afirmaram lidar com uma concorrência muito alta, onde prioritariamente, o menor preço é quem rege a negociação, de modo que a qualidade do produto oferecido torna-se secundária frente ao seu valor monetário.

No processo de licitação, as organizações participantes devem necessariamente atender o regulamento e ofertarem produtos compatíveis com as características exigidas pelas instituições, sendo escolhida àquela que além de cumprir as peculiaridades do estado, consiga garantir o menor preço, conforme estipula o Decreto Estadual nํ 45.085. Diante disso, cabe a organização ofertar o produto adequado às necessidades da instituição, cumprindo exatamente as orientações do edital, de modo a zelar pela qualidade do produto fornecido e pela imagem da empresa perante as instituições participantes do sistema de negociações.

\section{DISCUSSÃO}

Visando a comodidade do cliente e adaptando-se cada vez mais às suas necessidades, o comércio eletrônico, que anteriormente atendia a um nicho específico de mercado, precisou adequar-se à nova realidade econômica da sociedade e passou a ofertar todo tipo de produto e de serviço. Segundo O’brien (2010, p. 259), “uma empresa deve oferecer uma boa seleção de produtos e serviços atraentes a preços competitivos aos compradores da rede ou eles rapidamente irão sair da loja". Assim, devido a grande concorrência hoje vivenciada pelas organizações pertencentes ao comércio eletrônico, muitas delas deixaram de comercializar apenas um tipo de produto e passaram a investir em vários segmentos, formando uma gama de lojas de departamentos.

Conforme Laudon e Laudon (2007, p. 272), “o comércio eletrônico é ubíquo, o que significa que está disponível simplesmente em todos os lugares, em todos os momentos". A partir desta afirmação, é possível compreender que o fato de permanecer disponível vinte e quatro horas por dia, sete dias por semana, acabou tornando-se a principal vantagem competitiva do comércio eletrônico sob os empreendimentos físicos.

Mediante aos benefícios conceituados e exemplificados até o momento, destacam-se ainda neste segmento, barreiras tecnológicas, culturais, organizacionais e estruturais que envolvem todo o processo da comercialização eletrônica.

Ainda de acordo com Dornelas (2012), o baixo investimento necessário para desenvolver um negócio no comércio eletrônico, foi o principal responsável por despertar o interesse dos empreendedores neste tipo de comercialização. Com isso, muitas opções de negócio foram 
criadas e inúmeras oportunidades surgiram, beneficiando àqueles que tiveram a percepção de identificá-las e capacitação para mantê-las no concorrido mercado eletrônico. Desta forma, é possível compreender que o fato de investir em um mercado propenso ao crescimento não é sinônimo de sucesso, mas cabe ao empreendedor capacitar-se e buscar formas de concretizar o seu negócio, profissionalizando-o e legalizando-o, superando as barreiras organizacionais do comércio eletrônico e obtendo êxito em suas atividades.

\section{CONCLUSÃO}

Mediante a exposição dos dados bibliográficos, assim como a opinião dos empreendedores que trabalham diretamente com a Bolsa Eletrônica de Compras do Estado de São Paulo, pode-se concluir que embora haja pouca divulgação deste segmento de negócio, tão pouco das funcionalidades da BEC e do segmento G2B, este encontra-se em plena expansão, inclusive para micro e pequenos empresários.

Ainda que haja inúmeros benefícios entre negociar e comprar pela rede mundial de computadores, é importante salientar que como todo negócio, este segmento também apresenta riscos, cabendo ao interessado estudar o mercado e as oportunidades, atentando-se principalmente às barreiras que envolvem este processo.

\section{REFERÊNCIAS}

COSTA, E. E-government: o governo eletrônico no Brasil. Organizado por Florencia Ferrer e Paula Santos. São Paulo: Saraiva, 2004.

CRESWELL, J. W. Projeto de pesquisa: métodos qualitativo, quantitativo e misto. Porto Alegre: Artmed, 2007.

DORNELAS, J. C. A. Empreendedorismo: transformando ideias em negócios. 4. ed. Rio de Janeiro: Elsevier, 2012.

GIL, A. C. Como elaborar projetos de pesquisa. 5. ed. São Paulo: Atlas, 2010.

GODOY, A. S. Pesquisas qualitativas: tipos fundamentais. Revista Eletrônica de Administração. São Paulo, v.35, p. 20-29, Mai./Jul. 1995.

LAUDON, K. C.; LAUDON, J. P. Sistemas de informação gerenciais. 7. ed. São Paulo: Pearson, 2007. O'BRIEN, J. A. Sistemas de informação: e as decisões gerenciais na era da internet. 3. ed. São Paulo: Saraiva, 2010.

RAMOS, E. et al. E-commerce. 3. ed. Rio de Janeiro: FGV, 2011. 
RAMPAZZO, L. Metodologia científica: para alunos dos cursos de graduação e pós-graduação. 2. ed. São Paulo: Edições Loyola. 2004.

SAO PAULO. Decreto n.o 45.085, de 31 de julho de 2000. Institui, no âmbito do Estado, sistema eletrônico de contratações, dispõe sobre normas operacionais de realização de despesas. Disponível em: <http://http://www.jusbrasil.com.br/legislacao/133350/decreto-45085-00-saopaulo-sp>. Acesso em: 20 mar. 2013.

TURBAN, E.; KING, D. Comércio eletrônico: estratégia e gestão. São Paulo: Pearson, 2004. 